\title{
SOME ASPECTS OF THE STRENGTHENING OF EARTHQUAKE RISK BUILDINGS
}

\author{
William Toomath*
}

\begin{abstract}
:
It is suggested that a graded system of strengthening earthquake risk buildings based on public risk and the feasibility and economics of strengthening should be adopted. The social responsibility of the Architect in the strengthening project is also discussed.
\end{abstract}

The question might be asked - why should we bother to strengthen our older buildings against earthquake risk? Why not leave it to the normal process by which they will be replaced by new buildings as they become uneconomic or obsolete?

The answer is twofold. First, advances in seismic design and experience during the last decade or so indicate that a great number of our city buildings previously thought to be safe enough are probably not so in many earthquake conditions. And second, like it or not, we cannot afford to knock down all the older buildings and build new ones: that is just not feasible economically, nor desirable socially. So we have to face up to the problem in a social and urban context.

Today's much improved science of seismic design leads to the adoption of more stringent standards in building codes. Analysis of wider earthquake experience intensifies concern for levels of risk inherent in older structures. consequently, all but the newest buildings fall short in some respects of the minimum standards now held acceptable. The majority of our whole stock of buildings is therefore substandard, and a high proportion seriously so, in terms of the levels of risk now considered acceptable by the expert arbiters.

At such a scale, these major asset values cannot be written off and the buildings replaced with new. Social and economic factors would prevent it. Therefore our broad choices seem to be -

(1) To accept a greater degree of risk, related to other risk levels in modern urban life, and to only demolish the most seriously weak structures;

(2) To devise ways of strengthening whole structures in moderate cases when buildings are otherwise serviceable or of other value; and

(3) To modify existing buildings in a selective manner, by demolishing major risk areas while retaining and strengthening portions of intrinsic value, whether for use, historic association, aesthetic value or environmental conservation (one example is the proposed retention of only the auditorium of the old Wellington Town Hall building; preservation of the Hunter Building facades at Victoria University is another).

(4) In certain application, we may reduce the statistical risk by restricting the type of use of the building, or its frequency.

So, on the one hand, the community cannot afford to discard all buildings that are below our present idea of par. On the other, it would be prohibitively costly to strengthen all buildings up to present day par. Hence a graded system of degrees of strengthening may be adopted, ranging from full compliance with the current codes where economic feasibility is satisfactory and public risks are high, progressively reducing in standards as both feasibility and risks decline, moving through selective demolition and strengthening, down to acceptance of high risk in isolated cases where the building's value aesthetically or historically would be lost by strengthening and where the public risk is limited in extent - i.e. to live dangerously on occasion when it is worth it. But sometimes we should strengthen the best for posterity, taking no halfmeasures and as discreetly as possible.

At the everyday level, however, our city depends on innumerable run-of-the-mill masonry buildings of pre 1931 vintage and hence earthquake risks; workshops, warehouses, offices, shops. The degree of strengthening required could be related to the degree of human occupation; and in some cases a change of use could reduce the strengthening requirements for these buildings.

Apart from such aspects of functional need for the city's stock of older buildings, there is a strong case for trying to keep the city's character intact by the retention of typical and worthy buildings (or at least the old facades) in certain areas. It is important for people to feel a continuity with the past, to feel some stability recognisable in their surroundings. We should try to preserve much of the local character of our city, such as it is, for enjoyment by visitors as well as by ourselves.

Consider then, the price we might pay to be rid of all building hazards in our older buildings, if an extensive demolition policy were pursued. Whole localities would cease to exist, many old 
friends would be cut down, much variety of character, interest and visual richness would be lost - all the urban details that grow with age and add flavour to life in Wellington. Judicious strengthening which preserves this flavour, especially where it is still strong, should be among our aims.

Thus, in any strengthening project, an architect should play his part, not only in considering alternative uses for the building which right reduce the risk, but in responding to the building's character itself. Given an architect with a feeling for the history of his art, and with a respect for the intentions of his forerunner, much of that Wellington flavour might be secured.

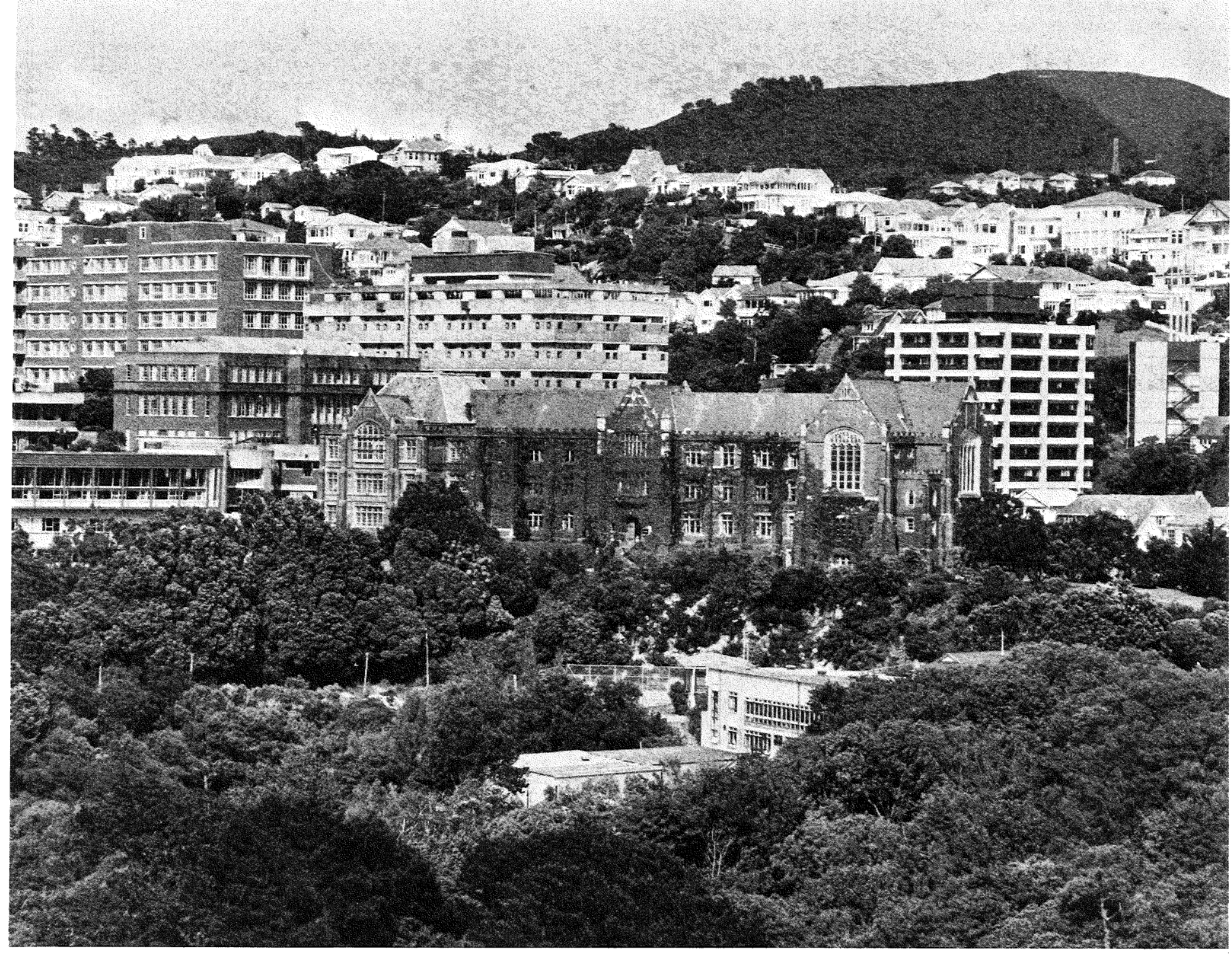

Victoria Universities Hunter Building Centre : also the subject of several studies. Criteria for the strengthenin of historic and commercial earthquake risk buildings may differ considerably 